\title{
A Laser-Based Multipass Absorption Sensor for Sub-ppm Detection of Methane, Acetylene and Ammonia
}

\author{
Wei Duan ${ }^{1}$, Fuwu Yan ${ }^{1}$, Yu Wang ${ }^{1,2}{ }^{\mathbb{D}}$, Hui Zhang ${ }^{3}$, Liuhao Ma ${ }^{1,3, * \mathbb{D}}$, Daxin Wen ${ }^{1}$, Wei Wang ${ }^{1}$, Gang Sheng ${ }^{1}$ \\ and Qiang Wang ${ }^{3, * \mathbb{D}}$
}

1 Hubei Key Laboratory of Advanced Technology for Automotive Components, School of Automotive Engineering, Wuhan University of Technology, Wuhan 430070, China; wei.duan@whut.edu.cn (W.D.); yanfuwu@vip.sina.com (F.Y.); yu.wang@whut.edu.cn (Y.W.); wendaxin@whut.edu.cn (D.W.); wwang1561988@whut.edu.cn (W.W.); shenggang@whut.edu.cn (G.S.)

2 Key Laboratory of Power Machinery and Engineering of Ministry of Education, Shanghai Jiao Tong University, Shanghai 200240, China

3 State Key Laboratory of Applied Optics, Changchun Institute of Optics, Fine Mechanics and Physics, Chinese Academy of Sciences, Changchun 130033, China; zhanghui195@mails.ucas.ac.cn

* Correspondence: liuhaoma@whut.edu.cn (L.M.); wangqiang@ciomp.ac.cn (Q.W.)

check for updates

Citation: Duan, W.; Yan, F.; Wang, Y.; Zhang, H.; Ma, L.; Wen, D.; Wang, W.; Sheng, G.; Wang, Q. A Laser-Based Multipass Absorption Sensor for Sub-ppm Detection of Methane, Acetylene and Ammonia. Sensors 2022, 22, 556. https://doi.org/ $10.3390 / \mathrm{s} 22020556$

Academic Editors: Xue Wang, Xinyu Li, Liang Ren, Qi Zhou, Jikui (Jack) Luo, Lei Zhang, He Tian, Hongwei Liu, Aiguo Song and Xinming Li

Received: 12 December 2021

Accepted: 8 January 2022

Published: 12 January 2022

Publisher's Note: MDPI stays neutral with regard to jurisdictional claims in published maps and institutional affiliations.

Copyright: (C) 2022 by the authors. Licensee MDPI, Basel, Switzerland. This article is an open access article distributed under the terms and conditions of the Creative Commons Attribution (CC BY) license (https:// creativecommons.org/licenses/by/ $4.0 /)$.

\begin{abstract}
A compact, sensitive laser-based absorption sensor for multispecies monitoring of methane $\left(\mathrm{CH}_{4}\right)$, acetylene $\left(\mathrm{C}_{2} \mathrm{H}_{2}\right)$ and ammonia $\left(\mathrm{NH}_{3}\right)$ was developed using a compact multipass gas cell. The gas cell is $8.8 \mathrm{~cm}$ long and has an effective optical path length of $3.0 \mathrm{~m}$ with a sampling volume of $75 \mathrm{~mL}$. The sensor is composed of three fiber-coupled distributed feedback lasers operating near $1512 \mathrm{~nm}, 1532 \mathrm{~nm}$ and $1654 \mathrm{~nm}$, an InGaAs photodetector and a custom-designed software for data acquisition, signal processing and display. The lasers were scanned over the target absorption features at $1 \mathrm{~Hz}$. First-harmonic-normalized wavelength modulation spectroscopy $(f=3 \mathrm{kHz})$ with the second harmonic detection (WMS-2f/1f) is employed to eliminate the unwanted power fluctuations of the transmitted laser caused by aerosol/particles scattering, absorption and beam-steering. The multispecies sensor has excellent linear responses $\left(R^{2}>0.997\right)$ within the gas concentration range of 1-1000 ppm and shows a detection limit of $0.32 \mathrm{ppm}$ for $\mathrm{CH}_{4}, 0.16 \mathrm{ppm}$ for $\mathrm{C}_{2} \mathrm{H}_{2}$ and $0.23 \mathrm{ppm}$ for $\mathrm{NH}_{3}$ at $1 \mathrm{~s}$ response time. The Allan-Werle deviation analysis verifies the long-term stability of the sensor, indicating a minimal detection limit of 20-34 ppb were achieved after 60-148 s integration time. Flow test of the portable multispecies sensor is also demonstrated in this work.
\end{abstract}

Keywords: multispecies sensor; sensitive detection; wavelength modulation spectroscopy; optical sensor

\section{Introduction}

Accurate knowledge of trace gas concentration is crucial for inflammable, explosive and poisonous gas leakage warning [1], medical breath diagnostics [2], environmental monitoring [3-5] and active control of combustion and propulsion systems [6,7]. The worldwide target for "Peak carbon dioxide emission" and "Carbon neutrality" further emphasizes the significance of trace gas sensing, particularly for greenhouse gases and atmospheric pollutants [8,9]. Methane $\left(\mathrm{CH}_{4}\right)$, a representative greenhouse gas, mainly comes from anthropogenic and natural sources such as production and transport of fossil fuels and agricultural practices [10]. Another light hydrocarbon $\mathrm{C}_{2} \mathrm{H}_{2}$ is widely known as a molecular growth agent towards large polycyclic aromatic hydrocarbons (PAH) precursor for soot formation and thus plays a very important role in soot formation [11]. Note that $\mathrm{C}_{2} \mathrm{H}_{2}$ is a typical combustion intermediate during incomplete combustion of hydrocarbon fuels [12].

Recently, $\mathrm{NH}_{3}$ has been recognized as a potential carbon-neutral fuel that can help to accelerate the reduction of greenhouse gas emissions [13]. However, $\mathrm{NH}_{3}$ is a prevalent atmospheric pollutant and its leakage would lead to the formation of ammonium salt, 
which will further contribute to the formation of particulate matter. Additionally, for stationary emission sources such as thermal power plant, $\mathrm{NH}_{3}$ is used as a reductant to convert the $\mathrm{NO}_{x}$ pollutant to $\mathrm{N}_{2}$. In practical applications, excessive spray of $\mathrm{NH}_{3}$ could be used which may cause the ammonia to escape. Therefore, precise and sensitive measurement of $\mathrm{CH}_{4}, \mathrm{C}_{2} \mathrm{H}_{2}$ and $\mathrm{NH}_{3}$ is crucial to not only the environmental monitoring but the evaluation of the combustion process.

Over the past decades, various techniques have been developed for quantitative measurements of gas concentrations, including electrochemical method [14], Fourier transform spectroscopy [15], non-dispersive infrared method [16], laser-based absorption and dispersion spectroscopy [17-20], photoacoustic and photothermal spectroscopy [21,22]. Many of these techniques have been transferred to commercially-available sensors and have been continuously improved to satisfy the increasing demand for higher detectivity, sensitivity and robustness. Among these techniques, laser absorption spectroscopy (LAS) represents one of the most widely-used and reliable methods due to its fast response, species-selectivity, high sensitivity, detectivity, robustness and relatively simple optical configuration [23].

For LAS-based sensors, direct absorption spectroscopy (DAS) and wavelength modulation spectroscopy (WMS) are two typical measurement schemes. DAS is a straightforward technique for gas detection. By baseline fitting to the transmitted absorption profile, the gas concentration can be quantified. However, the unexpected laser power fluctuations induced by laser systems and particles scattering/absorption from the target environment will definitely introduce unwanted interferences and extra uncertainties. Additionally, the detection limit of DAS is limited due to low-frequency noises. Note that WMS method overcomes the baseline fitting issue and improves the detectivity by shifting the detection bandwidth to higher frequencies (twice the modulation frequency) [24]. The WMS method with second harmonic signal ( $2 f$ ) detection (WMS-2 $f$ ) has been widely used for trace gas sensing. However, the $2 f$ signal magnitude will be influenced by the laser power fluctuations in addition to being sensitive to the photodetector shifts. By normalizing the second harmonic signal by the first harmonic signal which is simultaneously recorded (i.e., WMS-2f / $1 f$ ), the influence of optical power fluctuations can be largely eliminated [25-28]. Hence, the WMS- $2 f$ / $1 f$ method is favorable for trace gas detection.

Recent technical advancements of multipass gas cell and the mature telecommunication laser technologies provide a promising solution for developing trace gas sensors using a combination of distributed feedback (DFB) lasers and compact multipass gas cell [29-31]. Many efforts have been devoted to developing trace gas sensors using such kind of configurations. More specifically, Liu et al. developed a highly sensitive WMS-based $\mathrm{CH}_{4}$ sensor using a compact dense-pattern multipass cell for atmospheric $\mathrm{CH}_{4}$ measurement [32]. A measurement precision of $<79 \mathrm{ppb}$ per second was achieved and a minimum detection limit of $15 \mathrm{ppb}$ can be reached with an integrated time of $70 \mathrm{~s}$. Shao et al. presented a compact sensor using a single DFB laser near $2.3 \mu \mathrm{m}$ for simultaneous detection of $\mathrm{CO}$ and $\mathrm{CH}_{4}$ [33]. The sensor has a detectivity of ppb level with over two minutes averaging and has the advantage of high robustness which is achieved through utilizing the WMS$2 f / 1 f$ method. Sun et al. developed a highly sensitive acetylene sensor using optimized WMS technique and compact multipass cell [34]. Jin et al. reported a robust fiber-coupled sensor for remote dual-species measurement of $\mathrm{CH}_{4}$ and $\mathrm{C}_{2} \mathrm{H}_{2}$ using a combination of frequency-division multiplexing method and WMS-2f $/ 1 f$ [35]. Sub-ppm sensitivity with $1 \mathrm{~s}$ time resolution was achieved for both gas species. Guo et al. developed a portable sensor for in situ measurement of $\mathrm{NH}_{3}$ and applied the sensor for monitoring the flue gas of coke oven after Selective Catalytic Reduction (SCR) System [36]. Li et al. developed a portable and robust LAS-based sensor for dual species (i.e., $\mathrm{NH}_{3}$ and $\mathrm{H}_{2} \mathrm{O}$ ) measurements in the denitrification processes of thermal power plants [37]. Bai et al. proposed the development of a $\mathrm{NH}_{3}$ detection system with wide dynamics range based on numerical simulation [38]. Raza et al. performed simultaneous measurement of $\mathrm{NH}_{3}$ and $\mathrm{CO}$ at elevated temperature. At the temperature of $700 \mathrm{~K}$ and absorption length of $20 \mathrm{~cm}$, the noise equivalent 
absorption (NEA) coefficient of $3.5 \times 10^{-6} \mathrm{~cm}^{-1}$ for $\mathrm{CO}$ and $4.9 \times 10^{-7} \mathrm{~cm}^{-1}$ for $\mathrm{NH}_{3}$ was achieved [39]. Note that, the commercially-available mid-infrared (MIR), room temperature laser sources make it accessible to target the strong absorption features in the fundamental band. Although more sensitive sensors can be developed using the mid-infrared laser sources, the MIR lasers are too costly to be frequently and extensively used in practical applications. By implementing the low-cost DFB lasers and portable multipass gas cell, laser sensor with desired sensitivity and detectivity can be also developed with promising application potentials.

In this work, we report a sensitive sensor for simultaneous trace-gas detection of $\mathrm{CH}_{4}, \mathrm{C}_{2} \mathrm{H}_{2}$ and $\mathrm{NH}_{3}$ using multiple NIR DFB lasers and a compact multipass gas cell. Precise line selection was performed to select the appropriate line for detection. WMS- $2 f / 1 f$ strategy was adopted to achieve low-detection limit and high precision. The sensor shows a sub-ppm minimum detection limit (MDL) at the response time of $1.0 \mathrm{~s}$ for $\mathrm{CH}_{4}, \mathrm{C}_{2} \mathrm{H}_{2}$ and $\mathrm{NH}_{3}$, respectively. The lower detection limit can be further improved to $30-50 \mathrm{ppb}$ by averaging up to $100 \mathrm{~s}$. Flow test of the developed sensor under different gas concentrations was performed in this work, proving its high practicability to real-life applications.

\section{Spectroscopic Fundamentals}

The principle of laser absorption spectroscopy (LAS) has been well documented in previous literature [40]. Here, only a brief description is reproduced to clarify the nomenclature and abbreviations used in the current work. When the collimated, monochromatic laser radiation interacts with the target gas molecules in the vicinity of molecular resonance within a homogeneous environment of length $L(\mathrm{~cm})$, the fractional attenuation of incident radiation intensity is governed by the Beer-Lambert relation [40]:

$$
\alpha_{v}=-\ln \left(\frac{I_{t}}{I_{0}}\right)_{v}=k_{v} L=S_{i}(T) \phi_{v} P X_{a b s} L
$$

where $\alpha_{v}$ and $k_{v}\left(\mathrm{~cm}^{-1}\right)$ are the frequency-dependent absorbance and absorption coefficient at the optical frequency $v\left(\mathrm{~cm}^{-1}\right)$, respectively; $I_{0}$ and It indicate the intensities of the incident and the transmitted laser, respectively; $P(\mathrm{~atm})$ denotes the total gas pressure, $S_{i}(T)$ $\left(\mathrm{cm}^{-2} \mathrm{~atm}^{-1}\right)$ is the temperature dependent line-strength of the specific transition $i, \phi_{v}(\mathrm{~cm})$ represents the normalized line-shape function, $T$ and $X_{a b s}$ are the temperature and species concentration of the absorption gas of interest.

For trace gas sensing, wavelength modulation spectroscopy with second harmonic detection (WMS-2f) is a well-established LAS technique and has been widely used in lab-scale and practical environments due to its high signal-to-noise ratio (SNR). This method eliminates the low-frequency noises by shifting the detection bandwidth to higher frequencies $(>\mathrm{kHz})$, which is above the frequency range of many common noise sources [41]. Note that the improved first-harmonic-normalized wavelength modulation spectroscopy with the second harmonic detection (WMS- $2 f / 1 f$ ) is another alternative and promising method that eliminates the low-frequency noises. By normalization of the $2 f$ signal by the simultaneous $1 f$ detection, the $2 f / 1 f$ signal can be made immune to the spurious transmitted laser power fluctuations caused by aerosol/particles scattering, absorption and beam-steering.

The WMS-2f includes modulating the laser injection current near the absorption feature of the target species and isolating the $2 f$ signal by a lock-in amplifier. The peak height of the $2 f$ signal is used to infer gas properties. The modulation involves a slow linear scan and a rapid sinusoidal dither. The frequency $v(t)$ and intensity $I(t)$ of the incident laser can be expressed by:

$$
\begin{gathered}
v(t)=\bar{v}(t)+a \cos (\omega t) \\
I_{0}(t)=\bar{I}_{0}(t)\left[1+i_{0}(t) \cos \left(\omega t+\psi_{1}\right)+i_{2}(t) \cos \left(2 \omega t+\psi_{2}\right)\right]
\end{gathered}
$$

where $\bar{v}(t)\left(\mathrm{cm}^{-1}\right)$ is the laser center frequency of the scan signal, a $\left(\mathrm{cm}^{-1}\right)$ is the modulation depth, $\omega$ is the modulation frequency, $\overline{I_{0}}(t)$ is the averaged laser intensity, $i_{0}(t)$ is the 
intensity modulation amplitude normalized by $\overline{I_{0}}(t), i_{1}$ and $i_{2}$ represent the amplitudes of linear and non-linear intensity modulation, $\psi_{1}$ and $\psi_{2}$ denote the linear and non-linear phase shift between frequency modulation and intensity modulation.

When the modulated laser beam passes through the target species, the transmitted laser intensity $I_{t}(t)$ is given by:

$$
I_{t}(t)=I_{0}(t) \cdot \tau(\bar{v}+a \cos \omega t)
$$

where $\tau(\bar{v}+a \cos \omega t)$ is the transmission coefficient. The transmission coefficient can be expanded in a Fourier cosine series:

$$
\tau(\bar{v}+a \cos \omega t)=\sum_{k=0}^{\infty} H_{k}(\bar{v}, a) \cdot \cos (k \omega t)
$$

The magnitude of the $2 f$ and $1 f$ signal become:

$$
\begin{aligned}
& S_{2 f}=\frac{G \bar{I}_{0}}{2}\left\{\left[H_{2}+\frac{i_{0}}{2}\left(H_{1}+H_{3}\right) \cos \psi_{1}\right]^{2}+\left[\frac{i_{0}}{2}\left(H_{1}-H_{3}\right) \sin \psi_{1}\right]^{2}\right\}^{1 / 2} \\
& R_{1 f}=\frac{G \bar{I}_{0}}{2}\left\{\left[H_{1}+i_{0}\left(H_{0}+\frac{H_{2}}{2}\right) \cos \psi_{1}\right]^{2}+\left[i_{0}\left(H_{0}-\frac{H_{2}}{2}\right) \sin \psi_{1}\right]^{2}\right\}^{1 / 2}
\end{aligned}
$$

With detailed knowledge of the specific laser tuning characteristics and spectral properties of the selected absorption transitions, the $2 f / 1 f$ signal can be obtained by directly calculating the Fourier coefficient of the transmission coefficient and the phase shift between frequency modulation. Therefore, the simulated $2 f / 1 f$ signal reflects the experimental details. For the trace gas sensing with known temperature and pressure, gas concentration can be obtained.

\section{Sensor Configurations}

Optimal selection of absorption lines is essential to sensor design. As illustrated in Figure 1, the target species have wide absorption spectrum within the overtone, combination and fundamental bands from near-infrared to mid-infrared region. It is evident that there exist potential interferences from other species such as $\mathrm{H}_{2} \mathrm{O}, \mathrm{CO}, \mathrm{CO}_{2}$ and $\mathrm{NO}_{\mathrm{x}}$. Therefore, the first priority is to find absorption lines that have good spectral isolation from the interfering gas species. In addition, sufficient line-strength should be ensured. For a minimum detectable absorbance of $0.01 \%$, an effective absorption length of $3.0 \mathrm{~m}$ and required SNR of over 10 at ambient temperature and atmospheric pressure $(T=296 \mathrm{~K}$, $P=1 \mathrm{~atm})$, the line-strength should ensure the peak absorbance of 0.001 . Considering the criteria mentioned above, we finally select absorption line near $6046.95 \mathrm{~cm}^{-1}, 6534.36 \mathrm{~cm}^{-1}$ and $6612.70 \mathrm{~cm}^{-1}$ for detection of $\mathrm{CH}_{4}, \mathrm{C}_{2} \mathrm{H}_{2}$ and $\mathrm{NH}_{3}$, respectively.

Three continuous-wave $(\mathrm{CW})$, narrow linewidth $(<3 \mathrm{MHz})$, fiber-coupled DFB lasers (NTT Electronics) mounted in butterfly packages were used as the light sources to target the selected absorption lines of $\mathrm{CH}_{4}, \mathrm{C}_{2} \mathrm{H}_{2}$ and $\mathrm{NH}_{3}$. The laser tuning performance of the emission wavelength were characterized using a spectral analyzer (Yokogawa, AQ6370). Figure 2 depicts the measured wavenumber as a function of the injection current at several representative operation temperatures $\left(16-34^{\circ} \mathrm{C}\right)$ and the simulated absorption spectrum within the tuning range. The three DFB lasers can be tuned over the wavenumber range 6040-6049 $\mathrm{cm}^{-1}, 6529-6540 \mathrm{~cm}^{-1}$ and 6606-6620 $\mathrm{cm}^{-1}$, respectively. As illustrated in Figure 2, the absorption features of the selected lines can be precisely covered by adjusting the operation temperature and scanning the injection current simultaneously. The spectral simulations were performed based on the HITRAN 2020 database [42] at ambient temperature, atmospheric pressure, concentration of $10 \mathrm{ppm}$ and optical path length of $3 \mathrm{~m}$. As can be noted, the peak absorbances for the selected absorption lines are larger than 0.001 for 
sensitive detection using the wavelength modulation spectroscopy strategy. Additionally, it is evident to see that there exists no absorption interference from the other two species. The selected absorption line satisfies the measurement requirements.

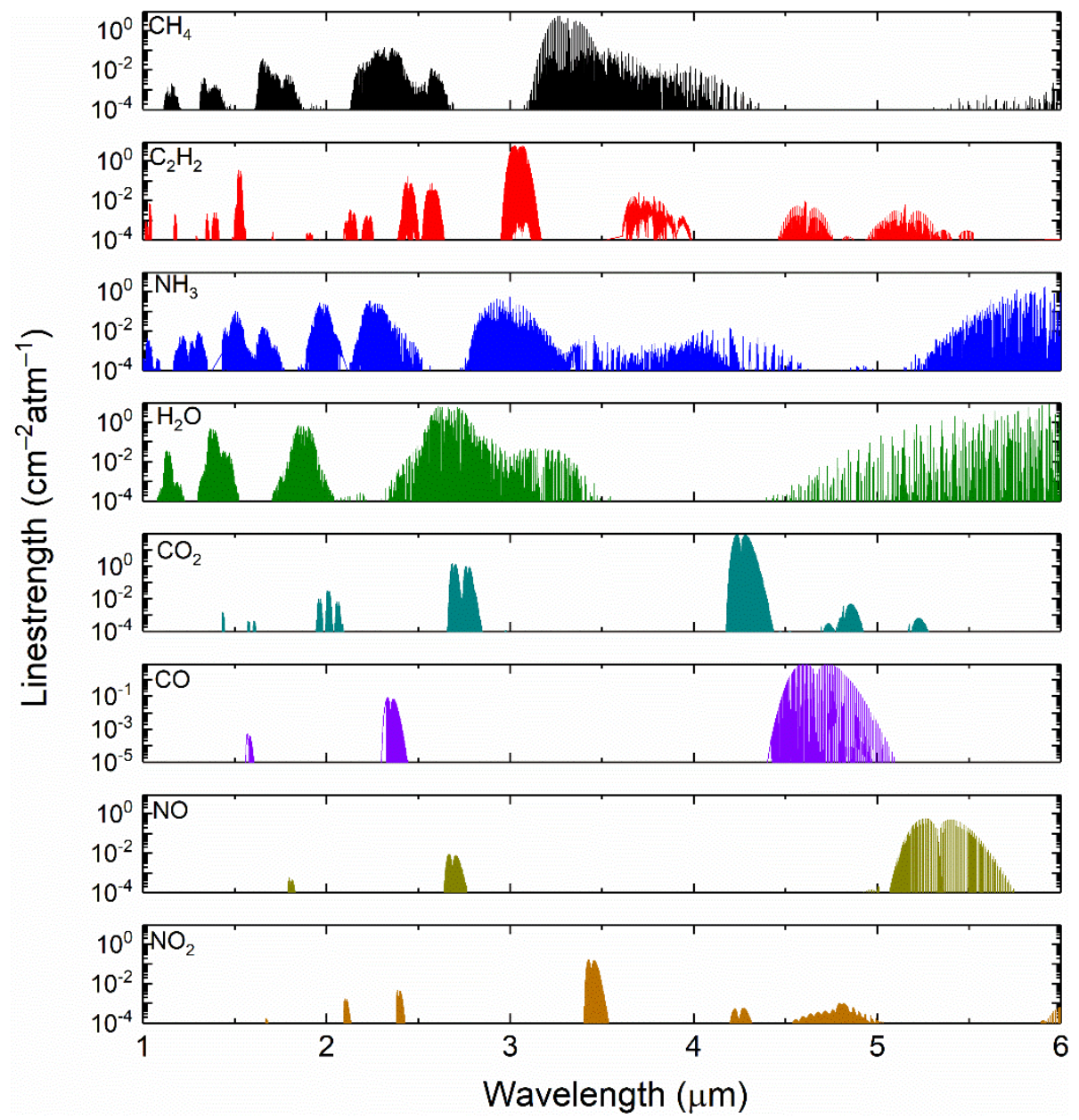

Figure 1. Absorption features of typical exhaust mixtures within near- and mid-infrared region (1-6 $\mu \mathrm{m})$ at $296 \mathrm{~K}$ based on HITRAN 2020 database [42].

Figure 3 depicts the optical configurations of the laser-based multispecies sensor. The operation temperature and injection current of the three near-infrared DFB lasers are precisely controlled by commercially-available low noise controllers (Stanford Research Systems, LDC501). A LabVIEW-based program with a data acquisition card (National Instruments, USB 6356) was used to generate the desired triangle-scan signals and sinusoidalmodulation signals, to record the signals from photodetectors and to perform the signal trigger synchronization. The three incident laser beams were coupled as one and directed to a compact multipass gas cell (MPGC) with an enclosed volume of $75 \mathrm{~mL}$. The MPGC includes two high-reflectivity quartz mirrors that are placed $8.8 \mathrm{~cm}$ apart from each other to have an effective absorption path length of $3.0 \mathrm{~m}$. The combined laser beam then interacts with the target gas molecules. The transmitted laser beams were then delivered to the InGaAs photodetector (Thorlabs, PDA20CS2). A digital lock-in filter coupled with a low-pass filter with cutoff frequency at $10 \mathrm{fs}$ (frequency of scan, i.e., $10 \mathrm{kHz}$ ) was applied to the raw detector signals to extract the harmonics of the WMS line shapes for each laser. 

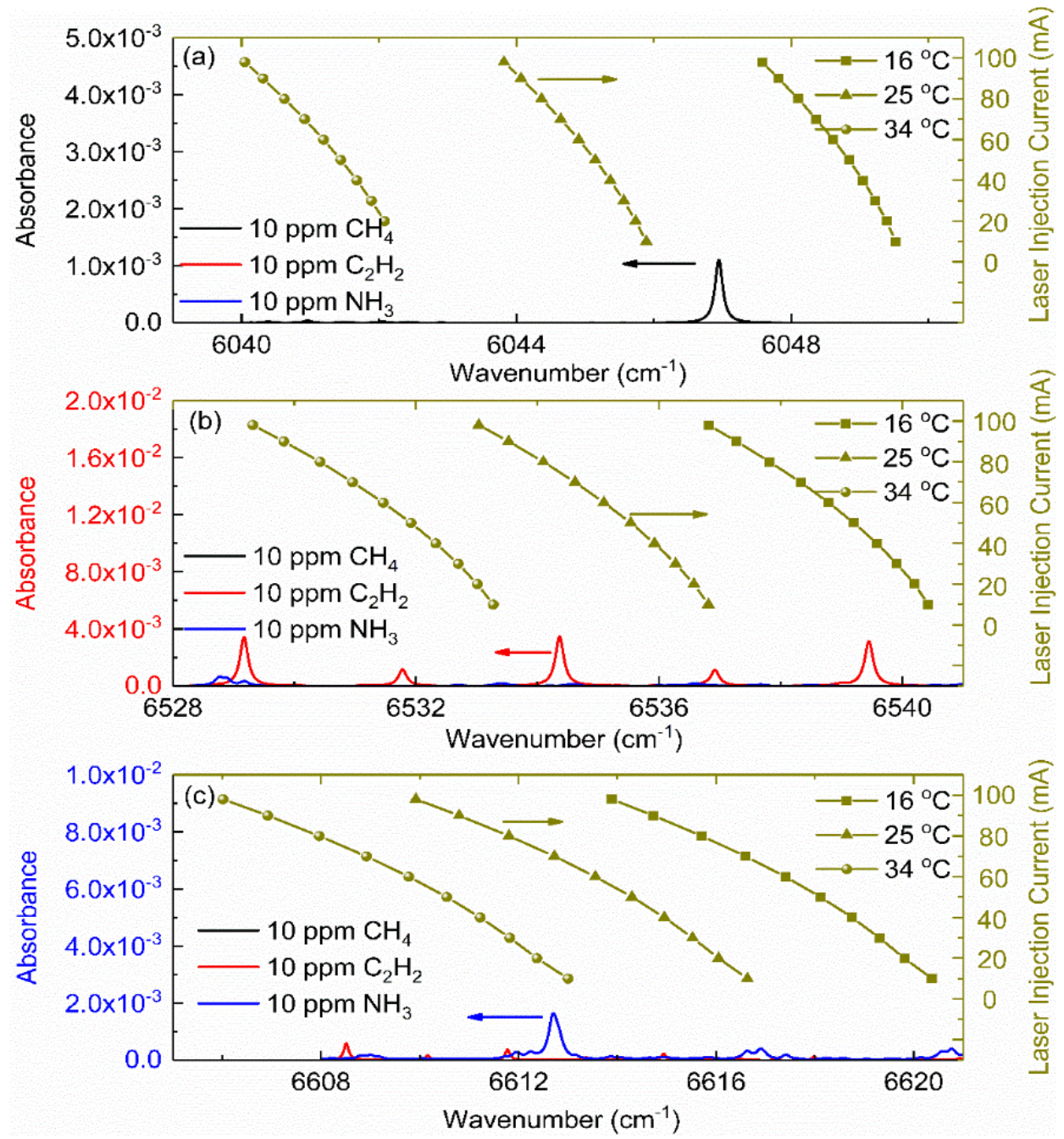

Figure 2. Characterization of the three DFB lasers' tuning range on top of the target absorption line of $\mathrm{CH}_{4}(\mathbf{a}), \mathrm{C}_{2} \mathrm{H}_{2}$ (b) and $\mathrm{NH}_{3}$ (c). The condition spectral simulation is set to be $L=3 \mathrm{~m}, P=1 \mathrm{~atm}$, $T=298.15 \mathrm{~K}, X_{\mathrm{abs}}=10 \mathrm{ppm}$.

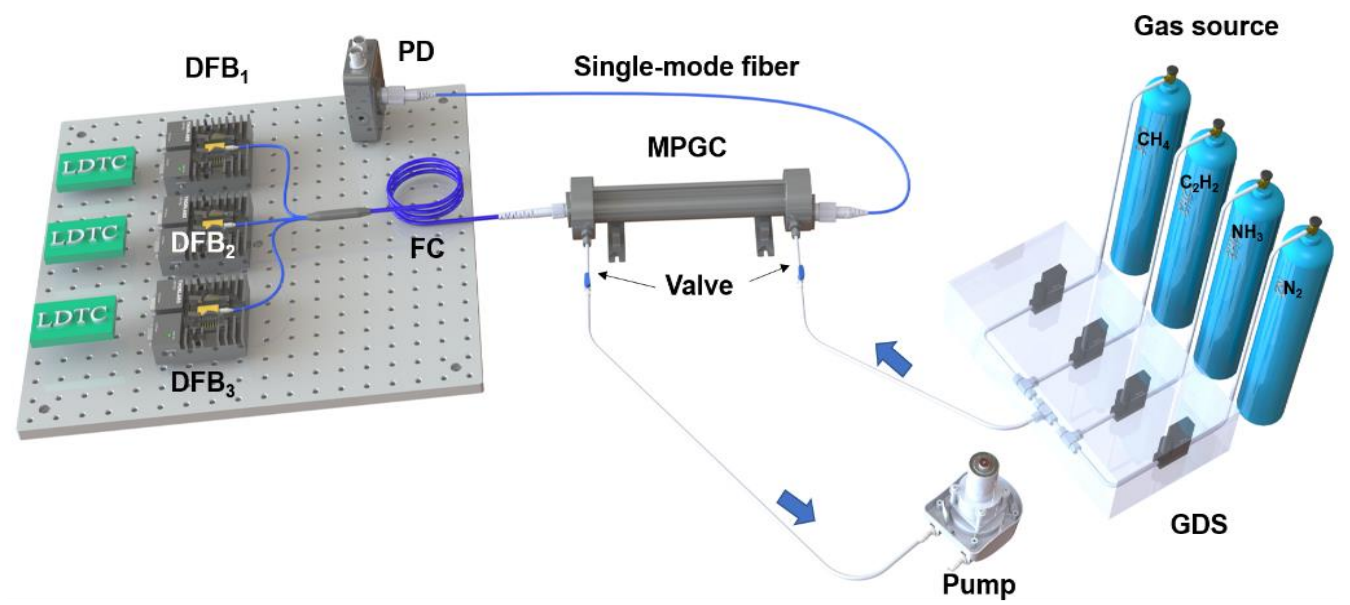

Figure 3. Schematic of the laser-based multipass absorption sensor. DFB, distributed feedback laser; LDTC, laser driver and temperature controller; PD, photodetector; FC, fiber coupler; MPGC, multipass gas cell; GDS, gas dilution system. 
For the experiments, reference standard gas is required. The concentrations of $\mathrm{CH}_{4}$, $\mathrm{C}_{2} \mathrm{H}_{2}$ and $\mathrm{NH}_{3}$ cylinders are calibrated to be $1000 \mathrm{ppm}$ and then diluted to gas samples with different concentrations using a highly accurate gas dilution system (LNI Swissgas, SONIMIX 7100). For the static experiments, the MPGC is pumped to vacuum by a mechanical pump and filled with the gas samples to ambient pressure at least three times. Note that all the measurements were performed at the ambient pressure of $1 \mathrm{~atm}$.

\section{Results and Discussion}

First-harmonic-normalized wavelength modulation spectroscopy with the second harmonic detection (WMS-2f/1f) was used for sensitive detection of multiple species. Each DFB laser was scanned to cover the selected absorption feature by a $1 \mathrm{~Hz}$ ramp waveform. A sinusoidal dither at $3 \mathrm{kHz}$ was superimposed to modulate the laser. For a fixed gas pressure, modulation frequency and a certain absorption feature, the magnitude of harmonic signals will be influenced by modulation depth. The multipass cell filled with a gas mixture sample of 100 ppm $\mathrm{CH}_{4}, 100$ ppm $\mathrm{C}_{2} \mathrm{H}_{2}$ and 100 ppm $\mathrm{NH}_{3}$ was used for searching the optimal modulation parameters by varying the peak-to-peak voltage of the sinusoidal modulation signal. Figure 4 shows the amplitude of $2 f$ and $2 f / 1 f$ signal as a function of modulation depth (in $\mathrm{mV}$ ) for three different gases. For any specific gas, the amplitudes of both signals experience an increase and subsequent decrease when the modulation depth increase from $60 \mathrm{mV}$ to $320 \mathrm{mV}$. For sensitive detection, the modulation depths were finally selected to be $160 \mathrm{mV}, 180 \mathrm{mV}$ and $120 \mathrm{mV}$ for $\mathrm{CH}_{4}, \mathrm{C}_{2} \mathrm{H}_{2}$ and $\mathrm{NH}_{3}$, respectively.
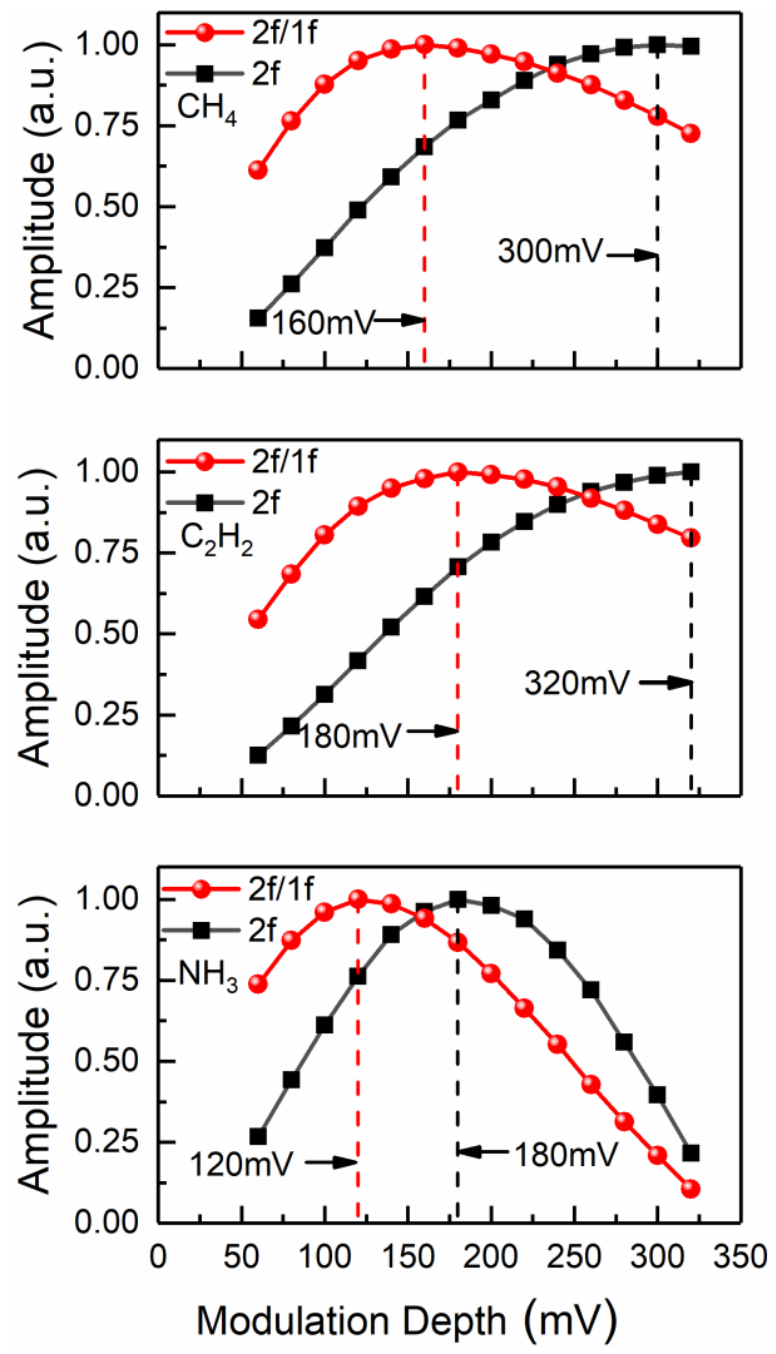

Figure 4. Normalized signal amplitude as a function of modulation depth. 
With the above-mentioned optimal modulation parameters, the sensor performance was comprehensively investigated by measuring the varied gas concentrations inside the multipass cell. Figure 5 depicts the representative WMS- $2 f / 1 f$, WMS- $2 f$ and WMS- $1 f$ signal profiles for gas concentrations of $100 \mathrm{ppm}$. High-fidelity signal can be clearly observed. Note that for the harmonic signals of $\mathrm{NH}_{3}$, there exist some raised peaks near the main peak, which is due to certain adjacent absorption lines.
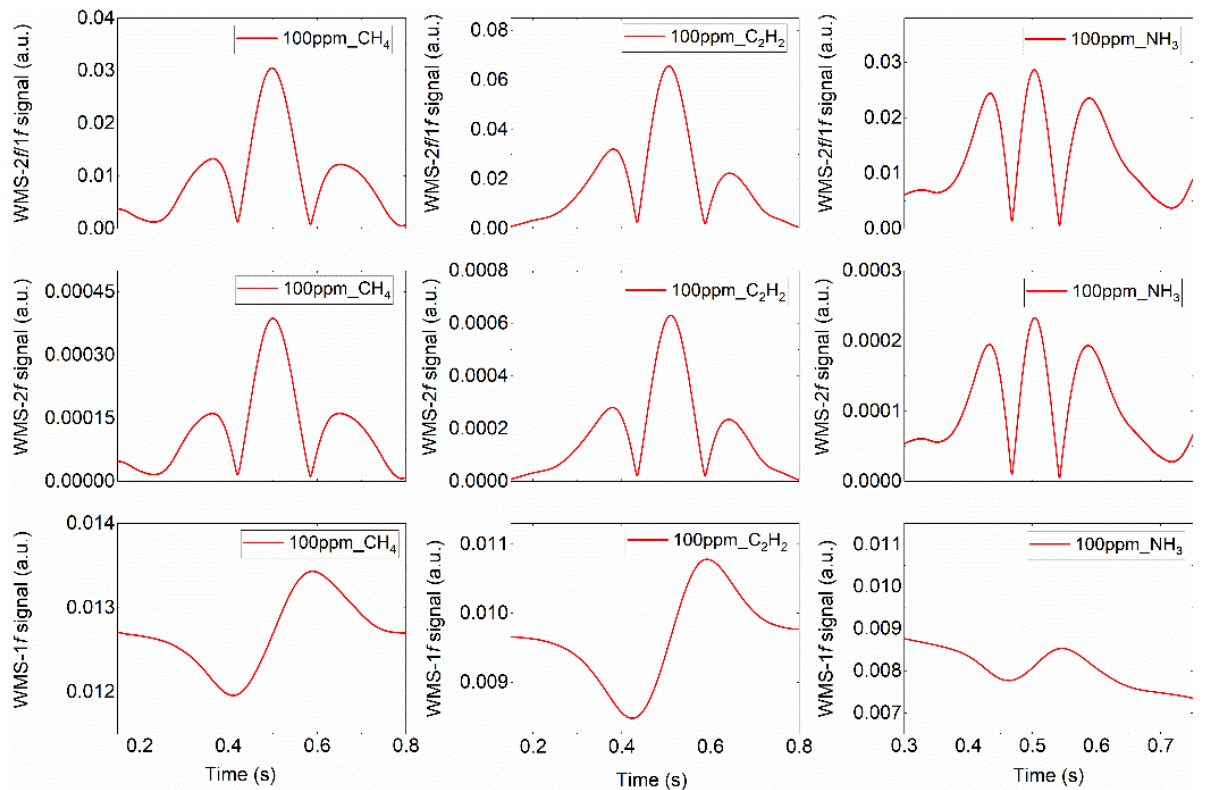

Figure 5. Representative WMS-2f / $1 f$, WMS-2 $f$ and WMS- $1 f$ signals for $100 \mathrm{ppm} \mathrm{CH}_{4}, \mathrm{C}_{2} \mathrm{H}_{2}$ and $\mathrm{NH}_{3}$ concentrations.

The measured amplitude of WMS-2f / $1 f$ signals at different $\mathrm{CH}_{4}, \mathrm{C}_{2} \mathrm{H}_{2}$ and $\mathrm{NH}_{3}$ concentrations were plotted in Figure 6. The solid lines represent the linear fitting to the experimentally-measured peak amplitude of the harmonic signals. All the R-square values for the linear fitting are estimated to be over 0.997, indicating an excellent linear response of the developed multispecies gas sensor. The linear fitting line can be used to estimate the detection limits of the current sensor by Allan-Werle deviation analysis, which will be elaborated.

To further evaluate the precision of current measurements, continuous measurements of $100 \mathrm{ppm} \mathrm{CH} \mathrm{CH}_{4}, \mathrm{C}_{2} \mathrm{H}_{2}$ and $\mathrm{NH}_{3}$ were performed at static environment for $30 \mathrm{~min}$. Figure 7 presents the frequency distribution (shown in histogram plot) of the measured data. It is clearly seen that the frequency distribution can be fitting by a Gaussian profile. The half width at half maximum (HWHM) of $0.4 \mathrm{ppm}, 0.2 \mathrm{ppm}$ and $0.3 \mathrm{ppm}$ for $\mathrm{CH}_{4}, \mathrm{C}_{2} \mathrm{H}_{2}$ and $\mathrm{NH}_{3}$, corresponding to a relative instrument precision level of $\sim 0.5 \%$.

In additional to precision evaluation, Allan-Werle deviation analysis were also performed to estimate the long-term stability of the sensor. The measurement detection limit was analyzed by evaluating the time-resolved variations of the $2 f / 1 f$ signal for gas concentrations of $100 \mathrm{ppm}$. It should be noted that the $1 \sigma$-noise voltage can be converted to gas concentration by exploiting the calibration curve illustrated in Figure 6 and time-resolved gas concentrations can be also directly used to get the Allan-Werle deviation curve. At a time resolution of $1 \mathrm{~s}$, the $\mathrm{MDL}$ of $\mathrm{CH}_{4}, \mathrm{C}_{2} \mathrm{H}_{2}$ and $\mathrm{NH}_{3}$ were determined to be $0.32 \mathrm{ppm}$, $0.16 \mathrm{ppm}$ and $0.23 \mathrm{ppm}$ for an effective absorption path length of $3.0 \mathrm{~m}$. It should be noted that the MDL can be further improved with the increase of integration time. As illustrated in Figure 8, at the measurement time of 60-100 s, the sensor achieved an MDL of 20-34 ppb. 

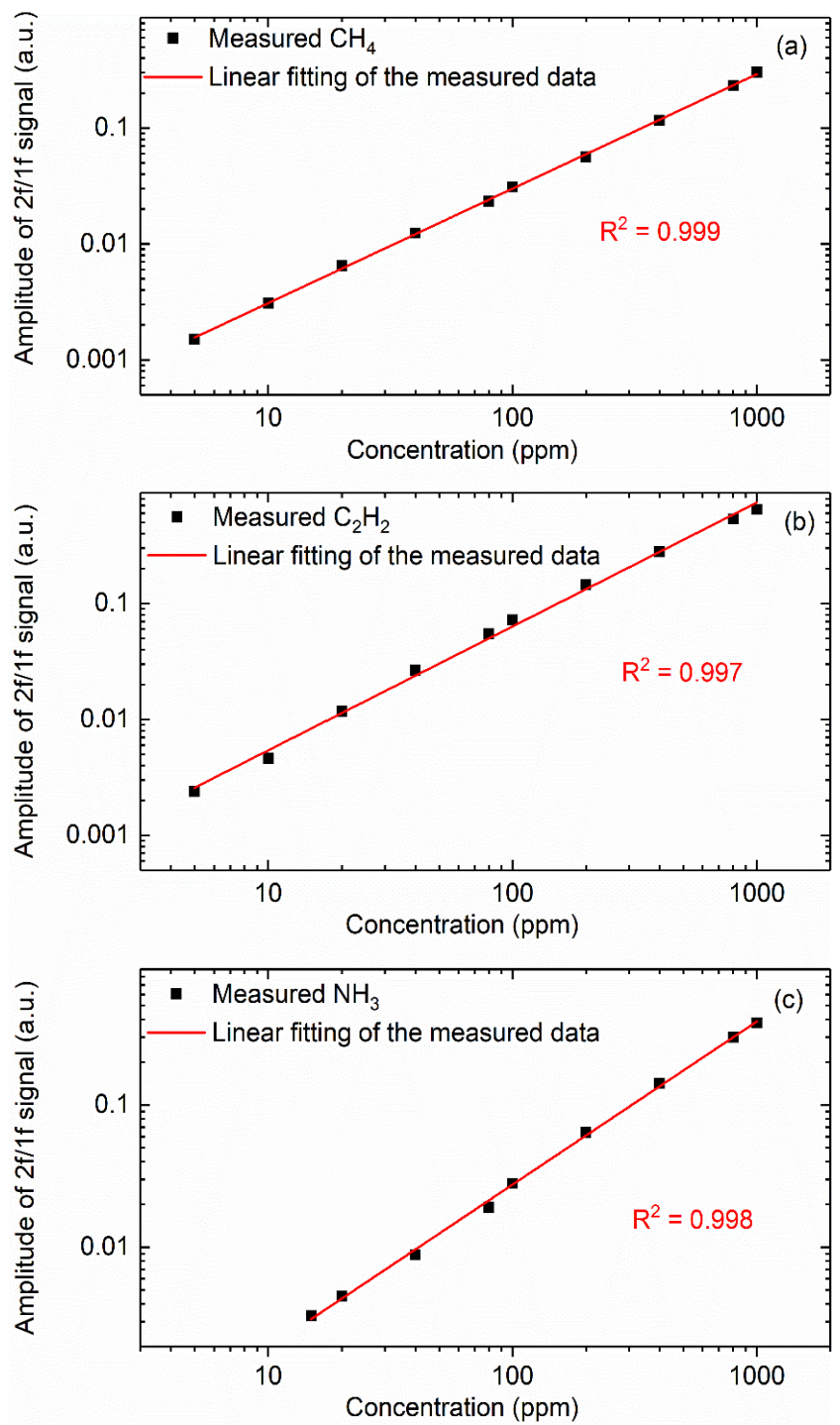

Figure 6. Measured amplitude of $2 f / 1 f$ signal as a function of the gas concentration: (a) $\mathrm{CH}_{4},(\mathbf{b}) \mathrm{C}_{2} \mathrm{H}_{2}$, (c) $\mathrm{NH}_{3}$.

The sensor's dynamic performance was also examined by monitoring varying gas concentrations (20-600 ppm) under gas flowing conditions. Figure 9 presents the measured time-resolved gas concentrations. The variations of gas concentration were successfully captured. More specifically, the rapid response of the measured $\mathrm{CH}_{4}$ and $\mathrm{C}_{2} \mathrm{H}_{2}$ was observed when the gas concentration increases. However, increase tendency is evidently slower for $\mathrm{NH}_{3}$ within the gradient region. This is because $\mathrm{NH}_{3}$ is a sticky gas and some amount of gas has been stuck to the wall of the gas cell during the gas loading. Considering the linearity, precision, long-term stability and dynamic performance, the sensor can provide simultaneous measurement of $\mathrm{CH}_{4}, \mathrm{C}_{2} \mathrm{H}_{2}$ and $\mathrm{NH}_{3}$ with sub-ppm-level sensitivity and dozens of ppb-level MDL.

There exists potential interference due to the absorption overlap when measuring $\mathrm{NH}_{3}$ concentration with the presence of high $\mathrm{C}_{2} \mathrm{H}_{2}$ concentration. Take the $\mathrm{C}_{2} \mathrm{H}_{2}$ concentration of 200 ppm, 500 ppm and 1000 ppm, for example, detection limit of $\mathrm{NH}_{3}$ is estimated to be $\sim 0.5 \mathrm{ppm}, \sim 1.2 \mathrm{ppm}$ and $2.6 \mathrm{ppm}$ at $1 \mathrm{~s}$ response time. For measurement of $100 \mathrm{ppm} \mathrm{NH}_{3}$, the measurement precision will remain the constant because the overlap near the peak absorbance is negligible if the noise level is unchanged. For measuring lower concentrations (e.g., $10 \mathrm{ppm}$ ), the precision will deteriorate from $\sim 0.5 \%$ to $1-2 \%$. For the simultaneous measurements of three gases, $\mathrm{CH}_{4}$ measurements will not be influenced by $\mathrm{C}_{2} \mathrm{H}_{2}$ and $\mathrm{NH}_{3}$ interference because there is no absorption overlap over the entire $\mathrm{CH}_{4}$ features. 
The interference will be non-negligible only when measuring $\mathrm{C}_{2} \mathrm{H}_{2}$ and $\mathrm{NH}_{3}$ under the condition that one specie concentration is over 100 times higher than the other. However, such interference can be quantitatively determined by using the multispectral fitting method to include the multiple absorption features of $\mathrm{C}_{2} \mathrm{H}_{2}$ and $\mathrm{NH}_{3}$.

In future applications, we mainly focus on the measurement at relatively mild condition, where the trace combustion exhaust and fuel leakage are emitted to the atmospheric environment. Note that the environmental fluctuations may drift the laser wavelength and fluctuate the laser intensity. In the current work, we used scanned-wavelength modulation spectroscopy to mitigate the effect of laser wavelength drift and $2 f / 1 f$ WMS strategy to eliminate the influence of received transmitted laser power. The measurement errors were observed to be within $1 \%$ for the gas concentration of $1-1000 \mathrm{ppm}$ in the presence of the environmental fluctuations based on repetitive experiments on different days. Therefore, we consider the environmental fluctuations have negligible effects on measurement errors.
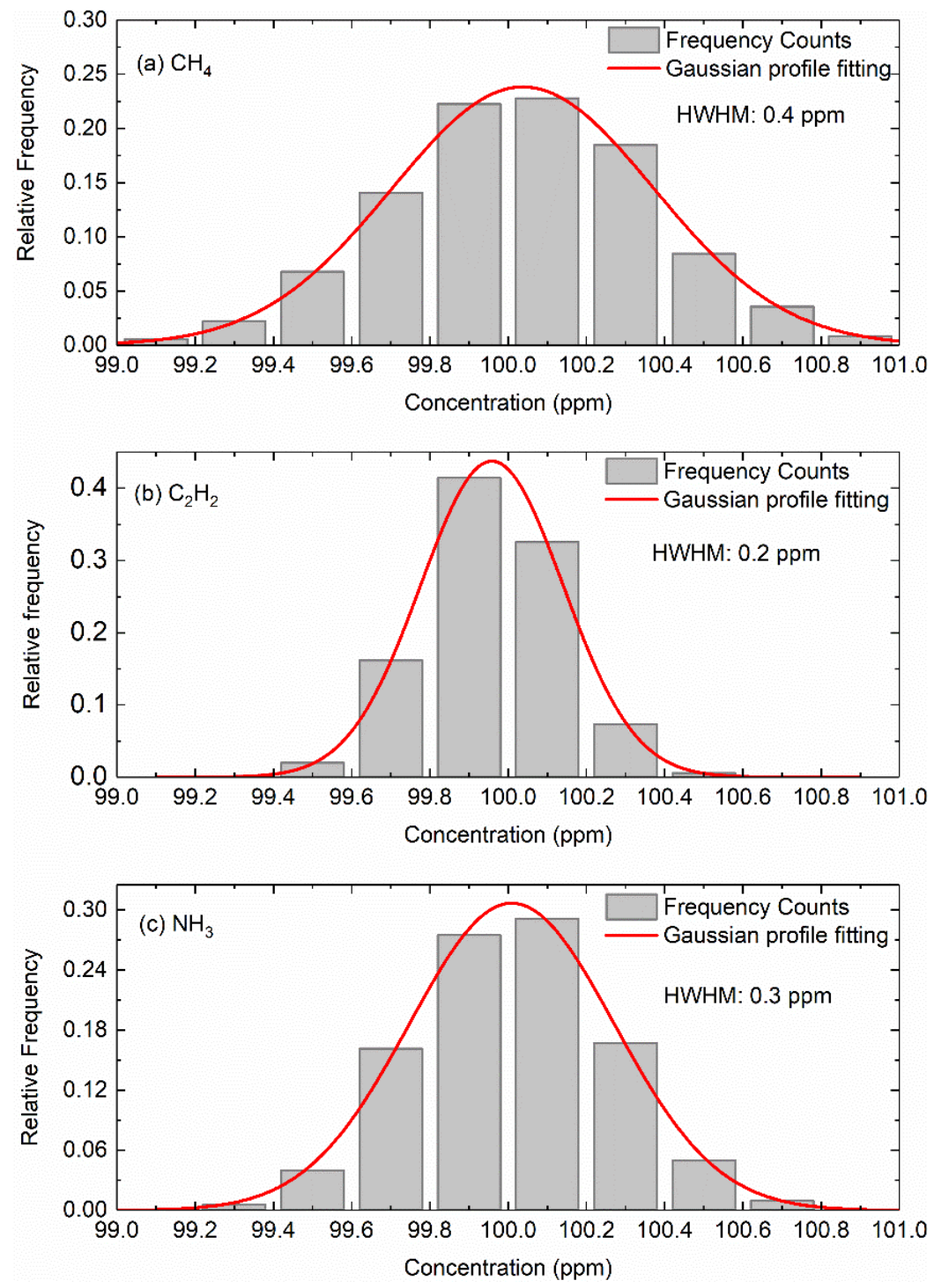

Figure 7. Frequency distribution of the measured data along with the Gaussian function fitting based on the time-resolved measurements of 100 ppm $\mathrm{CH}_{4}(\mathbf{a}), 100 \mathrm{ppm}_{2} \mathrm{H}_{2}$ (b) and $100 \mathrm{ppm} \mathrm{NH}$ (c) in the multipass gas cell. 

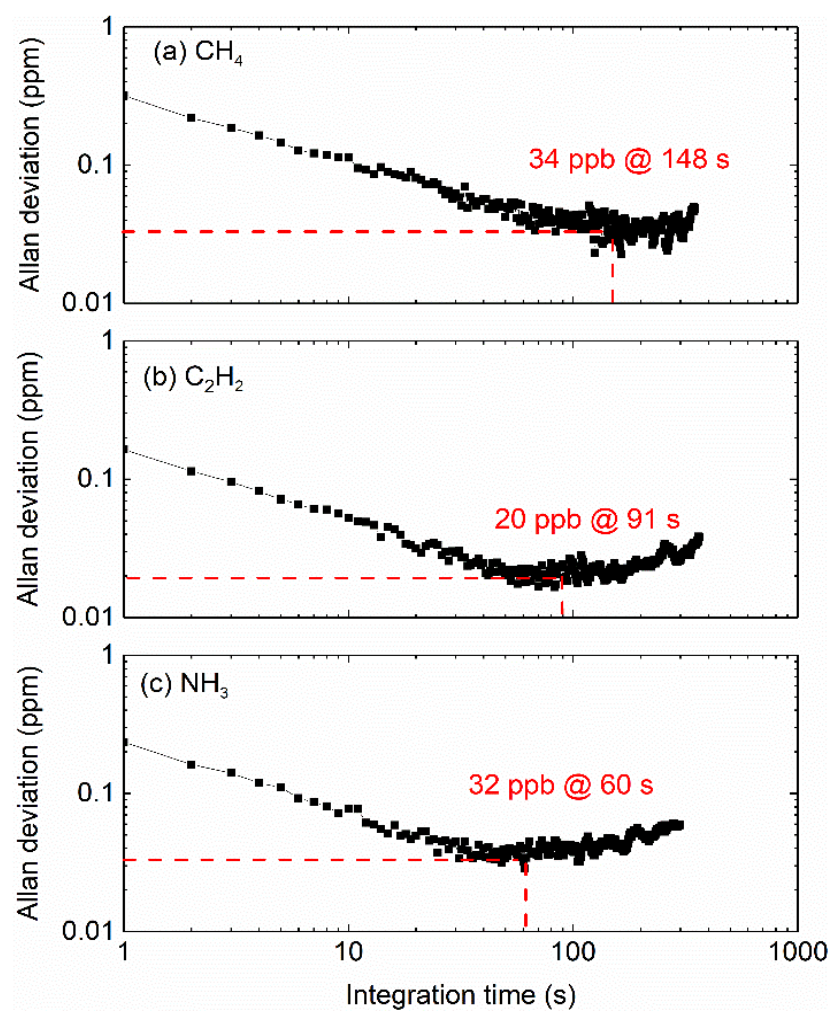

Figure 8. The Allan-Werle deviation curve of the current sensor for $\mathrm{CH}_{4}(\mathbf{a}), \mathrm{C}_{2} \mathrm{H}_{2}(\mathbf{b})$ and $\mathrm{NH}_{3}$ (c).
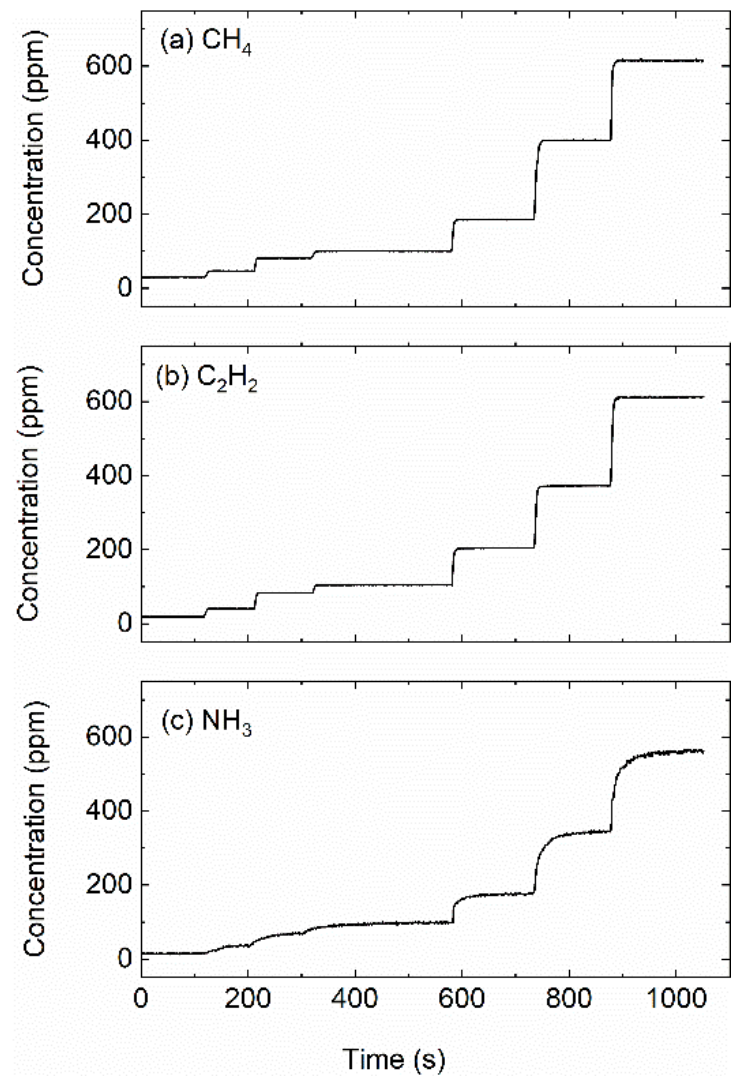

Figure 9. Gas flow test of the sensor for $\mathrm{CH}_{4}(\mathbf{a}), \mathrm{C}_{2} \mathrm{H}_{2}(\mathbf{b})$ and $\mathrm{NH}_{3}(\mathbf{c})$ at different concentrations. 


\section{Conclusions}

In this work, we presented a sensitive and precise laser absorption sensor for subppm detection of $\mathrm{CH}_{4}, \mathrm{C}_{2} \mathrm{H}_{2}$ and $\mathrm{NH}_{3}$ by implementing NIR DFB lasers and compact multipass cell. A systematic investigation of absorption lines within NIR and MIR region was conducted and absorption lines near $6049.96,6534.36$ and $6612.71 \mathrm{~cm}^{-1}$ were selected for $\mathrm{CH}_{4}, \mathrm{C}_{2} \mathrm{H}_{2}$ and $\mathrm{NH}_{3}$ detection, respectively. The selected lines are adequately immune to the interferences from other species and have sufficient line-strength to ensure desired detectivity at ambient temperature and atmospheric pressure. First-harmonic-normalized wavelength modulation spectroscopy with the second harmonic detection (WMS-2f / $1 f$ ) is used to ensure the robustness of measurement. Under the optimal modulation depth, good linear response $\left(R^{2}>0.997\right)$ was achieved within the gas concentration range of $1-1000 \mathrm{ppm}$. The multispecies sensor is estimate to have a precision of $0.5 \%$ for $30 \mathrm{~min}$ continuous measurement of $100 \mathrm{ppm}$ gas. MDLs of $0.32 \mathrm{ppm}, 0.16 \mathrm{ppm}$ and $0.23 \mathrm{ppm}$ were found at $1 \mathrm{~s}$ time resolution for $\mathrm{CH}_{4}, \mathrm{C}_{2} \mathrm{H}_{2}$ and $\mathrm{NH}_{3}$, respectively. By Allan-Werle deviation analysis, an improved MDL of 20-34 ppb can be found after integration time of 60-148 s. The sensitivity can be further improved by using the line-locked technique [43], adopting the hardware lock-in amplifier with higher time constant, or using advanced filtering techniques [44]. Besides the sub-ppm sensitivity and detectivity, the sensor was further demonstrated in flow gas conditions. Future work will involve the application of the sensor for monitoring the combustion exhaust from internal engines (e.g., natural gas engine, diesel engine) and further development of an FPGA-based, portable multispecies sensor.

Author Contributions: Conceptualization, L.M. and Q.W.; methodology, W.D. and H.Z.; software, H.Z. and Q.W.; validation, L.M., H.Z. and Q.W.; formal analysis, W.D., F.Y., L.M. and Q.W.; investigation, W.D., F.Y. and L.M.; resources, Q.W. and L.M.; data curation, L.M., H.Z. and Q.W.; writing—original draft preparation, W.D. and L.M.; writing-review and editing, L.M., Y.W. and Q.W.; visualization, G.S., D.W. and W.W.; supervision, L.M. and Q.W.; project administration, L.M. and Q.W.; funding acquisition, L.M., F.Y., Y.W. and Q.W. All authors have read and agreed to the published version of the manuscript.

Funding: This research was funded by National Natural Science Foundation of China (NSFC), grant number: 52106221, 62005267; Scientific Instrument Developing Project of the Chinese Academy of Sciences, grant number: YJKYYQ20190037, the Foundation of Key Laboratory of Power Machinery and Engineering, Ministry of Education, P.R. China, Second Comprehensive Scientific Investigation of the Qinghai-Tibet Plateau, grant number: 2019QZKK020802, Fundamental Research Funds for the Central Universities, grant number: WUT2021IVA016 and Startup funding of Wuhan University of Technology, grant number: 40120607.

Institutional Review Board Statement: Not applicable.

Informed Consent Statement: Not applicable.

Data Availability Statement: Not applicable.

Acknowledgments: The authors would like to thank Qinxue Nie for assisting the laser characterization and gas dilution.

Conflicts of Interest: The authors declare no conflict of interest.

\section{References}

1. Hodgkinson, J.; Tatam, R.P. Optical gas sensing: A review. Meas. Sci. Technol. 2013, 24, 59. [CrossRef]

2. Wang, C.J.; Sahay, P. Breath Analysis Using Laser Spectroscopic Techniques: Breath Biomarkers, Spectral Fingerprints, and Detection Limits. Sensors 2009, 9, 8230-8262. [CrossRef]

3. Ma, Y.F. Recent Advances in QEPAS and QEPTS Based Trace Gas Sensing: A Review. Front. Phys. 2020, 8, 12. [CrossRef]

4. Elia, A.; Lugara, P.M.; di Franco, C.; Spagnolo, V. Photoacoustic Techniques for Trace Gas Sensing Based on Semiconductor Laser Sources. Sensors 2009, 9, 9616-9628. [CrossRef]

5. Du, Z.H.; Zhang, S.; Li, J.Y.; Gao, N.; Tong, K.B. Mid-Infrared Tunable Laser-Based Broadband Fingerprint Absorption Spectroscopy for Trace Gas Sensing: A Review. Appl. Sci. 2019, 9, 338. [CrossRef] 
6. Goldenstein, C.S.; Spearrin, R.M.; Jeffries, J.B.; Hanson, R.K. Infrared laser-absorption sensing for combustion gases. Prog. Energy Combust. Sci. 2017, 60, 132-176. [CrossRef]

7. Hanson, R.K. Applications of quantitative laser sensors to kinetics, propulsion and practical energy systems. Proc. Combust. Inst. 2011, 33, 1-40. [CrossRef]

8. Xie, Y.C.; Hou, Z.M.; Liu, H.J.; Cao, C.; Qi, J.G. The sustainability assessment of CO2 capture, utilization and storage (CCUS) and the conversion of cropland to forestland program (CCFP) in the Water-Energy-Food (WEF) framework towards China's carbon neutrality by 2060. Environ. Earth Sci. 2021, 80, 17. [CrossRef]

9. Jia, K. Goals on the road: Instituional innovations in carbon peak and carbon neutrality. J. Chin. Econ. Bus. Stud. 2021, 13, 1-3. [CrossRef]

10. Available online: https://www.epa.gov/ghgemissions/overview-greenhouse-gases (accessed on 1 December 2021).

11. Wang, Y.; Chung, S.H. Soot formation in laminar counterflow flames. Prog. Energy Combust. Sci. 2019, 74, 152-238. [CrossRef]

12. Bento, D.S.; Thomson, K.A.; Gulder, O.L. Soot formation and temperature field structure in laminar propane-air diffusion flames at elevated pressures. Combust. Flame 2006, 145, 765-778. [CrossRef]

13. Valera-Medina, A.; Xiao, H.; Owen-Jones, M.; David, W.I.F.; Bowen, P.J. Ammonia for power. Prog. Energy Combust. Sci. 2018, 69, 63-102. [CrossRef]

14. Khan, M.A.H.; Rao, M.V.; Li, Q.L. Recent Advances in Electrochemical Sensors for Detecting Toxic $\mathrm{Gases} \mathrm{NO}_{2}, \mathrm{SO}_{2}$ and $\mathrm{H}_{2} \mathrm{~S}$ Sensors 2019, 19, 905. [CrossRef]

15. Erfan, M.; Sabry, Y.M.; Sakr, M.; Mortada, B.; Medhat, M.; Khalil, D. On-Chip Micro-Electro-Mechanical System Fourier Transform Infrared (MEMS FT-IR) Spectrometer-Based Gas Sensing. Appl. Spectmsc. 2016, 70, 897-904. [CrossRef]

16. De Biasio, M.; Leitner, R.; Krall, C.; Krivec, M.; Wilk, A.; Mizaikoff, B.; Waldner, R.; Starmans, F.; Maier, D. Ethylene Gas Sensing Using Non-Dispersive Infrared Spectroscopy. In Proceedings of the 15th IEEE Sensors Conference, Orlando, FL, USA, 30 October-3 November 2016; IEEE: Orlando, FL, USA, 2016.

17. Yao, C.; Wang, Z.; Wang, Q.; Bian, Y.; Chen, C.; Zhang, L.; Ren, W. Interband cascade laser absorption sensor for real-time monitoring of formaldehyde filtration by a nanofiber membrane. Appl. Opt. 2018, 57, 8005-8010. [CrossRef] [PubMed]

18. Wang, Z.; Cheong, K.P.; Li, M.; Wang, Q.; Ren, W. Theoretical and Experimental Study of Heterodyne Phase-Sensitive Dispersion Spectroscopy with an Injection-Current-Modulated Quantum Cascade Laser. Sensors 2020, 20, 6176. [CrossRef]

19. Martin-Mateos, P.; Acedo, P. Heterodyne phase-sensitive detection for calibration-free molecular dispersion spectroscopy. Opt. Express 2014, 22, 15143-15153. [CrossRef]

20. Hangauer, A.; Spinner, G.; Nikodem, M.; Wysocki, G. High frequency modulation capabilities and quasi single-sideband emission from a quantum cascade laser. Opt. Express 2014, 22, 23439-23455. [CrossRef]

21. Wang, Z.; Li, Z.; Ren, W. Quartz-enhanced photoacoustic detection of ethylene using a $10.5 \mu$ m quantum cascade laser. Opt. Express 2016, 24, 4143-4154. [CrossRef]

22. Yao, C.; Wang, Q.; Lin, Y.; Jin, W.; Xiao, L.; Gao, S.; Wang, Y.; Wang, P.; Ren, W. Photothermal CO detection in a hollow-core negative curvature fiber. Opt. Lett. 2019, 44, 4048-4051. [CrossRef] [PubMed]

23. Hanson, R.K.; Davidson, D.F. Recent advances in laser absorption and shock tube methods for studies of combustion chemistry. Prog. Energy Combust. Sci. 2014, 44, 103-114. [CrossRef]

24. Philippe, L.C.; Hanson, R.K. Laser diode wavelength-modulation spectroscopy for simultaneous measurement of temperature, pressure, and velocity in shock-heated oxygen flows. Appl. Opt. 1993, 32, 6090-6103. [CrossRef] [PubMed]

25. Rieker, G.B.; Jeffries, J.B.; Hanson, R.K. Calibration-free wavelength-modulation spectroscopy for measurements of gas temperature and concentration in harsh environments. Appl. Opt. 2009, 48, 5546-5560. [CrossRef]

26. Ren, W.; Jeffries, J.B.; Hanson, R.K. Temperature sensing in shock-heated evaporating aerosol using wavelength-modulation absorption spectroscopy of CO2near $2.7 \mu \mathrm{m}$. Meas. Sci. Technol. 2010, 21, 105603. [CrossRef]

27. Vanderover, J.; Wang, W.; Oehlschlaeger, M.A. A carbon monoxide and thermometry sensor based on mid-IR quantum-cascade laser wavelength-modulation absorption spectroscopy. Appl. Phys. B 2011, 103, 959-966. [CrossRef]

28. Liu, C.; Xu, L.; Li, F.; Cao, Z.; Tsekenis, S.A.; McCann, H. Resolution-doubled one-dimensional wavelength modulation spectroscopy tomography for flame flatness validation of a flat-flame burner. Appl. Phys. B 2015, 120, 407-416. [CrossRef]

29. Xu, K.; Zhao, X.; Wang, Z.; Chen, J.; Li, T.; Zheng, Z.; Ren, W. Multipass-assisted dual-comb gas sensor for multi-species detection using a free-running fiber laser. Appl. Phys. B 2020, 126, 39. [CrossRef]

30. Cui, R.Y.; Dong, L.; Wu, H.P.; Ma, W.G.; Xiao, L.T.; Jia, S.T.; Chen, W.D.; Tittel, F.K. Three-Dimensional Printed Miniature Fiber-Coupled Multipass Cells with Dense Spot Patterns for ppb-Level Methane Detection Using a Near-IR Diode Laser. Anal. Chem. 2020, 92, 13034-13041. [CrossRef]

31. Ren, W.; Jiang, W.Z.; Tittel, F.K. Single-QCL-based absorption sensor for simultaneous trace-gas detection of $\mathrm{CH}_{4}$ and $\mathrm{N}_{2} \mathrm{O}$. Appl. Phys. B-Lasers Opt. 2014, 117, 245-251. [CrossRef]

32. Liu, K.; Wang, L.; Tan, T.; Wang, G.S.; Zhang, W.J.; Chen, W.D.; Gao, X.M. Highly sensitive detection of methane by near-infrared laser absorption spectroscopy using a compact dense-pattern multipass cell. Sens. Actuator B-Chem. 2015, 220, 1000-1005. [CrossRef]

33. Shao, L.G.; Fang, B.; Zheng, F.; Qiu, X.B.; He, Q.S.; Wei, J.L.; Li, C.L.; Zhao, W.X. Simultaneous detection of atmospheric CO and $\mathrm{CH} 4$ based on TDLAS using a single $2.3 \mathrm{mu}$ m DFB laser. Spectroc. Acta Part A-Mol. Biomol. Spectr. 2019, 222, 6. [CrossRef] [PubMed] 
34. Sun, H.Y.; Ma, Y.F.; He, Y.; Qiao, S.D.; Yang, X.T.; Tittel, F.K. Highly sensitive acetylene detection based on a compact multi-pass gas cell and optimized wavelength modulation technique. Infrared Phys. Technol. 2019, 102, 5. [CrossRef]

35. Jin, W.L.; Zhang, H.; Hu, M.; Hu, M.P.; Wei, Y.B.; Liang, J.Q.; Kan, R.F.; Wang, Q. A Robust Optical Sensor for Remote Multi-Species Detection Combining Frequency-Division Multiplexing and Normalized Wavelength Modulation Spectroscopy. Sensors 2021, 21, 1073. [CrossRef]

36. Guo, X.Q.; Zheng, F.; Li, C.L.; Yang, X.F.; Li, N.; Liu, S.P.; Wei, J.L.; Qiu, X.B.; He, Q.S. A portable sensor for in-situ measurement of ammonia based on near-infrared laser absorption spectroscopy. Opt. Lasers Eng 2019, 115, 243-248. [CrossRef]

37. Li, J.Y.; Zhang, C.; Wei, Y.Y.; Du, Z.H.; Sun, F.H.; Ji, Y.; Yang, X.T.; Liu, C. In situ, portable and robust laser sensor for simultaneous measurement of ammonia, water vapor and temperature in denitrification processes of coal fired power plants. Sens. Actuator B-Chem. 2019, 305, 127533. [CrossRef]

38. Bai, Y.R.; Yu, H.J.; He, C.J.; Miao, Z.; Dou, R.; Zhang, Y.; Lin, X.C. A numerical simulation of a near-infrared three-channel trace ammonia detection system using hollow core photonic crystal fiber. Optik 2021, 227, 166006. [CrossRef]

39. Raza, M.; Ma, L.H.; Yao, S.C.; Chen, L.F.; Ren, W. High-temperature dual-species $\left(\mathrm{CO} / \mathrm{NH}_{3}\right)$ detection using calibration-free scanned-wavelength-modulation spectroscopy at $2.3 \mu \mathrm{m}$. Fuel 2021, 305, 121591. [CrossRef]

40. Hanson, R.K.; Spearrin, R.M.; Goldenstein, C.S. Spectroscopy and Optical Diagnostics for Gases; Springer International Publishing: Cham, Switzerland, 2016.

41. Reid, J.; Labrie, D. Second-harmonic detection with tunable diode lasers-Comparison of experiment and theory. Appl. Phys. B 1981, 26, 203-210. [CrossRef]

42. Gordon, I.E.; Rothman, L.S.; Hargreaves, R.J.; Hashemi, R.; Karlovets, E.V.; Skinner, F.M.; Conway, E.K.; Hill, C.; Kochanov, R.V.; Tan, Y.; et al. The HITRAN2020 molecular spectroscopic database. J. Quant. Spectrosc. Radiat. Transfer. 2021, $277,107949$. [CrossRef]

43. Wang, Q.; Wang, Z.; Ren, W. Wavelength-stabilization-based photoacoustic spectroscopy for methane detection. Meas. Sci. Technol. 2017, 28, 065102. [CrossRef]

44. Li, J.S.; Yu, B.L.; Zhao, W.X.; Chen, W.D. A Review of Signal Enhancement and Noise Reduction Techniques for Tunable Diode Laser Absorption Spectroscopy. Appl. Spectrosc. Rev. 2014, 49, 666-691. [CrossRef] 